\title{
Inhibition of Microglia-Derived Oxidative Stress by Ciliary Neurotrophic Factor Protects Dopamine Neurons In Vivo from $\mathrm{MPP}^{+}$Neurotoxicity
}

\author{
Jeong Yeob Baek ${ }^{1,+}$, Jae Yeong Jeong ${ }^{1,+}$, Kyoung In Kim ${ }^{1,+}$, So-Yoon Won ${ }^{2}$, \\ Young Cheul Chung ${ }^{3}$, Jin Han Nam ${ }^{3}$, Eun Ju Cho ${ }^{3}$, Tae-Beom Ahn ${ }^{4}$, Eugene Bok ${ }^{5}$,

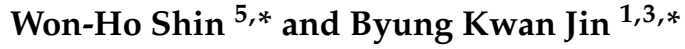 \\ 1 Department of Neuroscience, Graduate School, Kyung Hee University, Seoul 02447, Korea; \\ yeobe88@khu.ac.kr (J.Y.B.); jyoung0229@khu.ac.kr (J.Y.J.); basketis@khu.ac.kr (K.I.K.) \\ 2 Department of Biochemistry and Signaling Disorder Research Center, College of Medicine, \\ Chungbuk National University, Cheongju 28644, Korea; sywon@chungbuk.ac.kr \\ 3 Department of Biochemistry \& Molecular Biology, School of Medicine, Kyung Hee University, Seoul 02447, \\ Korea; ychung01@khu.ac.kr (Y.C.C.); namkoon02@gmail.com (J.H.N.); bioneun00@yonsei.ac.kr (E.J.C.) \\ 4 Department of Neurology, School of Medicine, Kyung Hee University, Seoul 02447, Korea; \\ doctorbrain@empal.com \\ 5 Department of Predictive Toxicology, Korea Institute of Toxicology, Daejeon 34114, Korea; \\ luckyars@naver.com \\ * Correspondence: whshin@kitox.re.kr (W.-H.S.); bkjin@khu.ac.kr (B.K.J.); \\ Tel.: +82-42-610-8088 (W.-H.S.); +82-2-961-9288 (B.K.J.) \\ + These authors contributed equally to this work.
}

Received: 17 September 2018; Accepted: 8 November 2018; Published: 10 November 2018

\begin{abstract}
We demonstrated that capsaicin (CAP), an agonist of transient receptor potential vanilloid subtype 1 (TRPV1), inhibits microglia activation and microglia-derived oxidative stress in the substantia nigra (SN) of $\mathrm{MPP}^{+}$-lesioned rat. However, the detailed mechanisms how microglia-derived oxidative stress is regulated by CAP remain to be determined. Here we report that ciliary neurotrophic factor (CNTF) endogenously produced by CAP-activated astrocytes through TRPV1, but not microglia, inhibits microglial activation and microglia-derived oxidative stress, as assessed by OX-6 and OX-42 immunostaining and hydroethidine staining, respectively, resulting in neuroprotection. The significant increase in levels of CNTF receptor alpha (CNTFR $\alpha$ ) expression was evident on microglia in the $\mathrm{MPP}^{+}$-lesioned rat $\mathrm{SN}$ and the observed beneficial effects of CNTF was abolished by treatment with CNTF receptor neutralizing antibody. It is therefore likely that CNTF can exert its effect via CNTFR $\alpha$ on microglia, which rescues dopamine neurons in the SN of $\mathrm{MPP}^{+}$-lesioned rats and ameliorates amphetamine-induced rotations. Immunohistochemical analysis revealed also a significantly increased expression of CNTFR $\alpha$ on microglia in the SN from human Parkinson's disease patients compared with age-matched controls, indicating that these findings may have relevance to the disease. These data suggest that CNTF originated from TRPV1 activated astrocytes may be beneficial to treat neurodegenerative disease associated with neuro-inflammation such as Parkinson's disease.
\end{abstract}

Keywords: Parkinson's disease; Microglia; Ciliary neurotrophic factor; Ciliary neurotrophic factor receptor; oxidative stress

\section{Introduction}

Microglia are the resident macrophages in the brain and spinal cord [1]. Many studies have demonstrated that activated microglia play a pivotal role in the cause and progression of Parkinson's 
disease (PD) characterized by the loss of dopamine (DA) neurons in the substantia nigra (SN) and motor dysfunctions [2-5]. Activated microglia exhibit large cell bodies with short, thick or no processes and exert neurotoxic effects by producing and releasing reactive oxygen species (ROS), inflammatory cytokines, which consequently triggers oxidative stress and severe inflammation. Microglia-derived oxidative stress and inflammation are involved in degeneration of DA neurons in the $\mathrm{SN}$ of patients with PD [3-8] and in the 1-methyl-4-phenylpyridinium $\left(\mathrm{MPP}^{+}\right)$-lesioned rats [9].

Transient receptor potential vanilloid subtype 1 (TRPV1), the capsaicin (CAP) receptor, is involved in pain perception and is highly expressed in sensory neurons [10]. TRPV1 is also present in the brain $[11,12]$ including DA neurons and astrocytes in the $\mathrm{SN}$ of intact and $\mathrm{MPP}^{+}$-lesioned rat and patients with PD [13]. We recently showed that TRPV1 activation by CAP contributes to DA neuronal survival by inhibiting microglia-derived oxidative stress in the $\mathrm{MPP}^{+}$-lesioned SN [9]. The study also demonstrated that pharmacological inhibition of TRPV1 activation by the TRPV1 antagonist capsazepine attenuated CAP-induced neuro-protection and inhibition of microglia-derived ROS production, indicating TRPV1-dependent effects of CAP. CAP has also been found to decrease intracellular ROS levels in myoblasts [14] and apoptosis in hippocampal neurons [15], collectively suggesting that CAP-induced TRPV1 activation may regulate oxidative stress. By contrast, several studies showed TRPV1-independent effects of CAP on glial cells. Pharmacological blockade by capsazepine or genetic deficiency of TRPV1 did not influence CAP-induced suppression of the production of prostaglandin 2 ( $\mathrm{PGE}_{2}$ ), inducible nitric oxide synthase (iNOS) and cyclooxygenase-2 (COX-2), and free radical formation in activated microglia and macrophages [16-18].

Ciliary neurotrophic factor (CNTF) is expressed in astrocytes [19-21] and microglia [22,23]. CNTF was found to stimulate astrocytes to secret fibroblast growth factor-2 [24] and rat microglia to secret glial cell line-derived neurotrophic factor [25], which suggest that CNTF exerts effects on glial cells to promote motor neuron survival [26-28]. CNTF attenuated microglial activation in optic nerve lesion [29] and increased motor neuron survival by reducing expression of microglial COX-2 related to oxidative stress [25]. CNTF exhibits biological functions through its own receptor, which consists of three subunits: CNTF receptor alpha (CNTFR $\alpha)$, Glycoprotein 130, and Leukemia inhibitory factor receptor [30]. CNTFR $\alpha$ is expressed on astrocytes [20,31,32] and microglia [25,33]. Activation of CNTFR $\alpha$ by CNTF enhanced microglial PGE $_{2}$ secretion and COX-2 protein expression in cultured mouse microglia [33]. We have recently demonstrated expression of CNTFR $\alpha$ in DA neurons in the SN of intact and $\mathrm{MPP}^{+}$-lesioned rats and of patients with PD [13]. Endogenous CNTF produced by TRPV1 activation on astrocytes acts through CNTFR $\alpha$ on DA neurons in the SN in vivo of $\mathrm{MPP}^{+}$-lesioned rats, resulting in neuro-protection and behavioral recovery [13]. CNTF also regulates microglia activation [25,33-36]. Here we report that endogenous CNTF originating from astrocytic TRPV1 activation by CAP inhibits microglial activation and microglia-derived oxidative stress in vivo by acting through CNTFR $\alpha$ on microglia, in consequence, rescuing DA neurons and improving motor recovery in the $\mathrm{MPP}^{+}$-lesioned rat model of $\mathrm{PD}$. The present data delve deeper into understanding the novel neuroprotective mechanism by which CAP inhibits microglia-derived ROS production and oxidative stress via astrocytic TRPV1-derived CNTF, which is acting via CNTFR $\alpha$ on microglia.

\section{Results}

2.1. TRPV1 Activation by Capsaicin Prevents Degeneration of DA Neurons and Inhibits Microglial Activation In Vivo in $M P P^{+}$-Lesioned Rat

Rats unilaterally received $\mathrm{MPP}^{+}$or PBS as a control in the medial forebrain bundle (MFB). At 2 weeks after $\mathrm{MPP}^{+}$injection, analysis by $\mathrm{TH}$ immunohistochemistry revealed $51 \%$ reduction in density of $\mathrm{TH}^{+}$fibers in the striatum (Figure $1 \mathrm{~A}, \mathrm{G}, \mathrm{S}$ ), and loss of $\mathrm{TH}^{+}$cells by $67 \%$ and $\mathrm{Nissl}^{+}$cells by $58 \%$ in the SN (Figure 1B-D,H-J,T), concomitant with amphetamine-induced rotations (Figure 1U), compared to PBS control. In $\mathrm{MPP}^{+}$lesioned rat, the TRPV1 agonist, CAP increased the density of striatal $\mathrm{TH}^{+}$fiber by $53 \%$ (Figure $1 \mathrm{M}, \mathrm{S}$ ), and the number of $\mathrm{TH}^{+}$cells by $58 \%$ and $\mathrm{Nissl}^{+}$cells by $46 \%$ 
in the $\mathrm{SN}$, respectively (Figure $1 \mathrm{~N}-\mathrm{P}, \mathrm{T}$ ) and ameliorated amphetamine-induced rotations (Figure 1U), compared to vehicle-treated control.
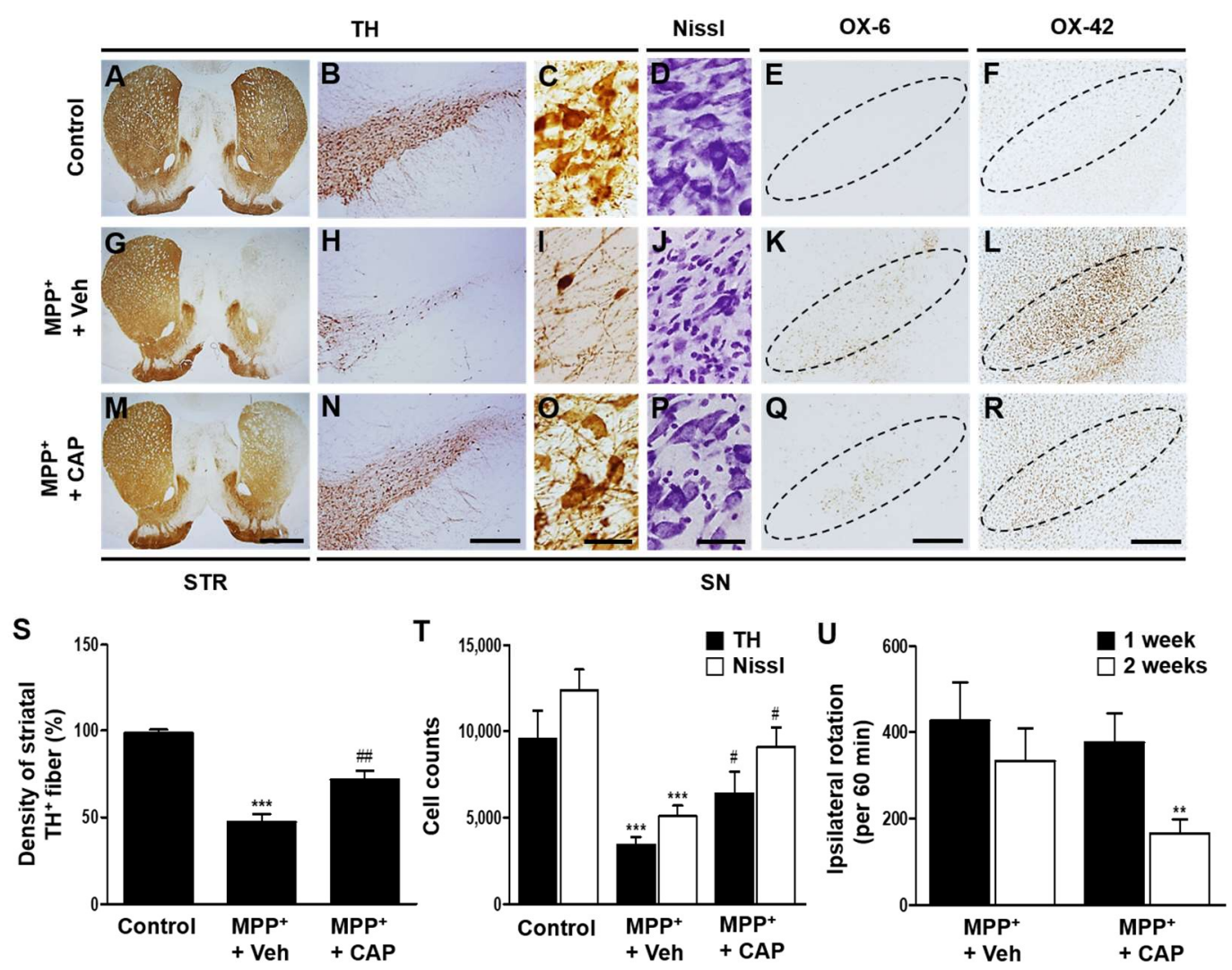

Figure 1. TRPV1 activation by capsaicin produces DA neuroprotection and reduces microglial activation in vivo in $\mathrm{MPP}^{+}$-lesioned rat. $\mathrm{MPP}^{+}$was unilaterally injected into the rat medial forebrain bundle (MFB) followed by intraperitoneal (i.p.) treatment of capsaicin (CAP: $1 \mathrm{mg} / \mathrm{kg}$ ) or vehicle (Veh) at 8 days post $\mathrm{MPP}^{+}$injection and a continuous single injection per day for 7 days. Rats were transcardially perfused after the last amphetamine-induced rotation experiment. (A-R) Photomicrographs of $\mathrm{TH}^{+}$fibers $(\mathbf{A}, \mathbf{G}, \mathbf{M})$ in the striatum (STR), and $\mathrm{TH}^{+}(\mathbf{B}, \mathbf{C}, \mathbf{H}, \mathbf{I}, \mathbf{N}, \mathbf{O}), \mathrm{Nissl}^{+}$ $(\mathrm{D}, \mathrm{J}, \mathrm{P}), \mathrm{OX}_{-} 6^{+}(\mathrm{E}, \mathrm{K}, \mathrm{Q})$ and $\mathrm{OX}-42^{+}(\mathrm{F}, \mathrm{L}, \mathbf{R})$ cells in the substantia nigra (SN). (S) Optical density of striatal $\mathrm{TH}^{+}$fibers. One way ANOVA $[\mathrm{F}(2,19)=26.92, p<0.0001]$ and Newman-Keuls analysis, ${ }^{* * *} p<0.001$, significantly different from control, ${ }^{\# \#} p<0.01$, significantly different from $\mathrm{MPP}^{+}+$Veh. (T) Number of $\mathrm{TH}^{+}$or Nissl ${ }^{+}$cells in the SN. One way ANOVA $\left[\mathrm{F}_{\mathrm{TH}}(2,17)=10.29, p=0.0012 ; \mathrm{F}_{\mathrm{Nissl}}(2,21)\right.$ $=12.63, p=0.0003]$ and Newman-Keuls analysis, ${ }^{* * *} p<0.001$, significantly different from control; ${ }^{\#} p<0.05$, significantly different from $\mathrm{MPP}^{+}+$Veh. (U) Cumulative amphetamine-induced ipsilateral rotations. Student $t$-Test analysis, ${ }^{* *} p<0.01(t=2.785, \mathrm{df}=30)$, significantly different from 1 week. Dotted lines indicate SN. Scale bars: $1 \mathrm{~mm}(\mathbf{A}, \mathbf{G}, \mathbf{M}), 400 \mu \mathrm{m}(\mathbf{B}, \mathbf{E}, \mathbf{F}, \mathbf{H}, \mathbf{K}, \mathbf{L}, \mathbf{N}, \mathbf{Q}, \mathbf{R}), 40 \mu \mathrm{m}(\mathbf{C}, \mathbf{D}, \mathbf{I}, \mathbf{J}, \mathbf{O}, \mathbf{P})$. Mean \pm S.E.M; (S) $n=6$ to 9 ; (T) $n=4$ to 8 ; (U) $n=12$ to 16 .

Given the neurotoxicity of activated microglia on DA neurons in the MPP+-lesioned SN [9], we hypothesized that $\mathrm{MPP}^{+}$neurotoxicity is in parallel with microglial activation in vivo. We found that $\mathrm{MPP}^{+}$-induced degeneration of DA neurons was accompanied by microglial activation as visualized by OX-6 (marker for activated microglia) and OX-42 (general marker for microglia) immunostaining in the $\mathrm{SN}$ (Figure $1 \mathrm{~K}, \mathrm{~L}$ ). CAP treatment decreased the immunoreactivity of $\mathrm{OX}-6^{+}$and OX- $42^{+}$cells in the $\mathrm{SN}$ at 2 weeks post $\mathrm{MPP}^{+}$injection compared to vehicle-treated $\mathrm{MPP}^{+}$-lesioned $\mathrm{SN}$ (Figure 1Q,R). 
2.2. Astrocytic TRPV1 Knockdown by shRNA Alters DA Neuronal Survival and Microglial Activation In Vivo in $M P P^{+}$-Lesioned Rat

As astrocytic TRPV1 activation by CAP contributes to DA neuronal survival in vivo [13], we wondered whether it could exert neuroprotection by regulating microglial activation. To test this hypothesis, astrocytic TRPV1 function was selectively and efficiently inhibited by a lentivirus carrying a small hairpin-forming interference RNA (shRNA) targeted against TRPV1 (shTRPV1) [13] (also see Section 4.10). The virus also contained DNA encoding a fluorescent marker, EGFP, which permitted visualization of the location and amount of viral infection.

To examine the selectivity and efficacy of shRNA in vivo, we stereotaxically injected $\mathrm{MPP}^{+}$and control scrambled shRNA (shCtrl) in the SN (see Section 4.3). We observed EGFP expression of shCtrl mainly within astrocytes 7 days post $\mathrm{MPP}^{+}$injection (Figure S1A,B). shTRPV1 selectively and efficiently inhibited TRPV1 expression primarily within astrocytes in the $\mathrm{SN}$ of $\mathrm{MPP}^{+}$-lesioned rat (Figure S1C,D). To evaluate the role of astrocytic TRPV1 on DA neurons in the SN, control scrambled shRNA (shCtrl) or shTRPV1 was ipsilaterally injected into the SN immediately after the unilateral MFB injection of $\mathrm{MPP}^{+}$. In the CAP-treated $\mathrm{MPP}^{+}$-lesioned rats, shTRPV1 decreased the density of $\mathrm{TH}^{+}$fibers by $54 \%$ in the striatum (Figure $2 \mathrm{~A}, \mathrm{G}, \mathrm{M}$ ), and the numbers of $\mathrm{TH}^{+}$cells by $69 \%$ and $\mathrm{Niss}^{+}$cells by $76 \%$ in the $\mathrm{SN}$ (Figure 2B-D,H-J,N) as well as reducing functional recovery (Figure 2O) compared to shCtrl.
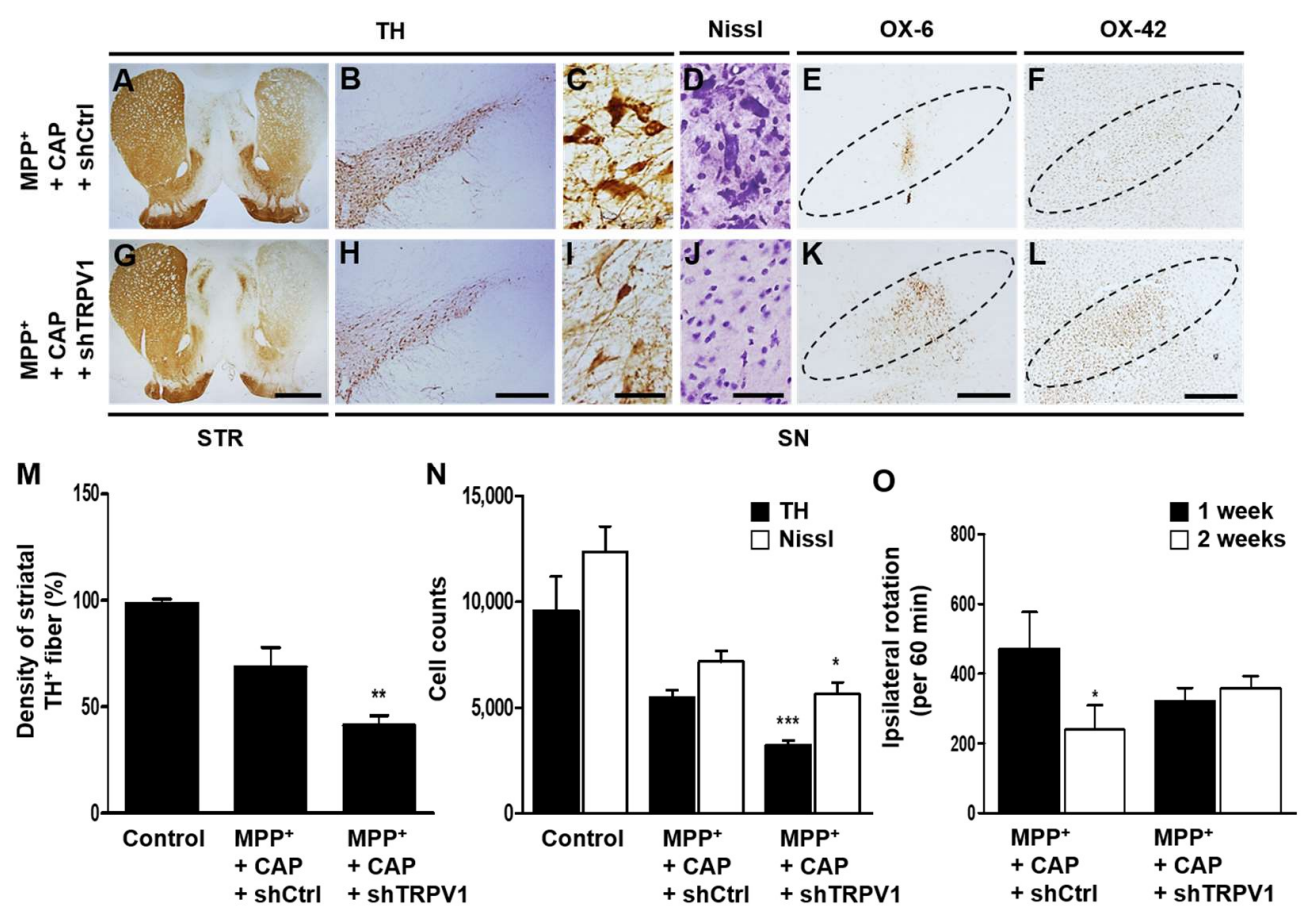

Figure 2. Knockdown of astrocytic TRPV1 induces degeneration on DA neurons and increase of microglial activation in vivo in $\mathrm{MPP}^{+}$-lesioned rat. $\mathrm{MPP}^{+}$was unilaterally injected into the rat MFB followed by injection of shCtrl (control) or shTRPV1 into the SN. All rats i.p. received CAP at 8 days post $\mathrm{MPP}^{+}$injection and a continuous single injection per day for 7 days. Rats were transcardially perfused after the last amphetamine-induced rotation experiment. (A-L) Photomicrographs of $\mathrm{TH}^{+}$ fibers $(\mathbf{A}, \mathbf{G})$ in the STR, and $\mathrm{TH}^{+}(\mathbf{B}, \mathbf{C}, \mathbf{H}, \mathbf{I}), \mathrm{Niss}^{+}(\mathbf{D}, \mathbf{J}), \mathrm{OX}_{-} 6^{+}(\mathbf{E}, \mathbf{K})$ and OX-42 ${ }^{+}(\mathbf{F}, \mathbf{L})$ cells in the SN. (M) Optical density of striatal $\mathrm{TH}^{+}$fibers. Student $t$-Test analysis, ${ }^{* *} p<0.01(t=2.782, \mathrm{df}=11)$, significantly different from $\mathrm{MPP}^{+}+\mathrm{CAP}+\operatorname{shCtrl}$. (N) Number of $\mathrm{TH}^{+}$or Nissl ${ }^{+}$cells in the SN. Student $t$-Test analysis, ${ }^{*} p<0.05(t=1.968, \mathrm{df}=10),{ }^{* * *} p<0.001(t=5.792, \mathrm{df}=10)$, significantly different from $\mathrm{MPP}^{+}+\mathrm{CAP}+\operatorname{shCtrl}$. (O) Cumulative amphetamine-induced ipsilateral rotations. Student $t$-Test analysis, ${ }^{*} p<0.05(t=1.837, \mathrm{df}=10)$, significantly different from 1 week. Dotted lines indicate SN. Scale bars: $1 \mathrm{~mm}(\mathbf{A}, \mathbf{G}), 400 \mu \mathrm{m}(\mathbf{B}, \mathbf{E}, \mathbf{F}, \mathbf{H}, \mathbf{K}, \mathbf{L}), 40 \mu \mathrm{m}(\mathbf{C}, \mathbf{D}, \mathbf{I}, \mathbf{J})$. Mean \pm S.E.M.; $(\mathbf{M}) n=6$ to $7 ;(\mathbf{N}) n=5$ to $7 ;(\mathbf{O}) n=6$ to 8 . 
In parallel with aggravation of DA neuronal loss and behavioral deficits by shTRPV1, astrocytic TRPV1 deficiency significantly increased immunostaining intensity of OX-6 ${ }^{+}$(Figure $2 \mathrm{~K}$ ) and OX-42 (Figure 2L) cells in the SN compared with shCtrl-treated control rats. Collectively, these results indicate that inhibition of microglial activation by astrocytic TRPV1 activation might contribute to neuroprotection and motor recovery.

\subsection{CAP Treatment Is Unable to Change Basal Levels of CNTF on Microglia in the SN In Vivo of $M P P^{+}$-Lesioned Rat}

As CNTF has neuro-protective properties [37], and inhibits microglial activation [29] and/or microglia-derived oxidative stress [25], CNTF expression was assessed in the absence or presence of $\mathrm{CAP}$ in the $\mathrm{SN}$ in vivo of $\mathrm{MPP}^{+}$-lesioned rat. At 2 weeks post $\mathrm{MPP}^{+}$injection, analysis by immunohistochemical staining showed that CNTF expression in $\mathrm{GFAP}^{+}$astrocytes was significantly higher in the rat SN compared to control (Figure 3A,B). CNTF expression in $\mathrm{TH}^{+}$neurons was significantly reduced (Figure 3C,D), whereas basal level of CNTF expression in OX-42 $2^{+}$microglia was unchanged (Figure 3E,F) compare to control. In CAP-treated $\mathrm{MPP}^{+}$-lesioned SN, CNTF expression in both $\mathrm{GFAP}^{+}$astrocytes (Figure $3 \mathrm{~A}, \mathrm{~B}$ ) and $\mathrm{TH}^{+}$neurons (Figure $3 \mathrm{C}, \mathrm{D}$ ) was significantly increased, whereas CNTF expression in OX-42+ microglia was relatively unchanged (Figure 3E,F) compared to vehicle-treated $\mathrm{MPP}^{+}$-lesioned SN. Collectively, the results indicate that CAP induces expression of CNTF originated from astrocytes, but not microglia. Knockdown of astrocytic TRPV1 reduced CNTF expression in the absence or presence of CAP in the $\mathrm{SN}$ of $\mathrm{MPP}^{+}$-lesioned rat (data not shown), supporting our recent findings of astrocytic TRPV1 activation-derived CNTF expression [13].

\subsection{CNTFR Neutralization Alters Neuroprotection and Microglial Activation in the SN In Vivo in} $M P P^{+}$-Lesioned Rat

As CNTF primarily functions via CNTFR $\alpha$ [30], we examined if CNTF could exert its effect on microglia through CNTFR $\alpha$ expressed on microglia. Immunohistochemical analysis showed a significant increase in the level of CNTFR $\alpha$ expression in OX- $42^{+}$cells in the $\mathrm{SN}$ of $\mathrm{MPP}^{+}$-lesioned rats, compared with control (Figure 4A-C). CNTFR $\alpha$ in Iba- $1^{+}$microglia was also significantly expressed in the SN of PD brain compared to age-matched human control brain (Figure 4D-F; Table 1), suggesting the possible relevance to PD.

Table 1. Human postmortem tissues used for immunofluorescence in Figure 4D-F.

\begin{tabular}{ccccccc}
\hline Sample No. & Final Diagnosis & Age & Sex & PMD & Staining & Tissue \\
\hline $04-424$ & & 75.1 & F & 22.5 & & \\
$08-026$ & Control & 67.3 & F & 24 & & \\
$07-787$ & & 66.5 & M & 19 & Iba-1 + CNTFR $\alpha$ & SN \\
09-260 & & 66.8 & F & 20 & & \\
V11-042 & PD & 72.1 & M & 25 & & \\
V11-007 & & 74 & F & 14 & & \\
\hline
\end{tabular}

M, Male; F, Female; PMD, Postmortem delays; SN, Substantia nigra.

Accordingly, we tested the effects of CNTFR $\alpha$ on microglial activation. CNTFR $\alpha$ neutralizing antibody (CNTFR $\alpha$ NAb) was unilaterally injected to block CNTF actions in the ipsilateral rat SN at 1 week after unilateral MFB injection of $\mathrm{MPP}^{+}$. Non-specific IgG was used as a control. CAP-induced neuro-protection and motor recovery were diminished as assessed by the density of $\mathrm{TH}^{+}$fibers by $38 \%$ in the striatum (Figure $5 \mathrm{~A}, \mathrm{G}, \mathrm{M}$ ), and the numbers of $\mathrm{TH}^{+}$cells by $39 \%$ and $\mathrm{Niss}^{+}$cells by $63 \%$ in the SN (Figure 5B-D,H-J,N) and amphetamine-induced rotations (Figure 5O) in $\mathrm{MPP}^{+}$-lesioned rats treated with CNTFR $\alpha$ NAb compared with non-specific IgG control rats. In parallel, in the $\mathrm{CAP}$-treated $\mathrm{MPP}^{+}$-lesioned rats, CNTFR $\alpha \mathrm{NAb}$ was found to increase immunostaining intensity of OX- $6^{+}$(Figure $5 \mathrm{~K}$ ) and OX-42+ (Figure 5L) cells in the SN, compared with non-specific IgG-treated 
respective control rats (Figure 5E,F). Taken together, these results indicate that CAP-induced astrocytic TRPV1-derived CNTF attenuates microglial activation through microglial CNTFR $\alpha$.

A
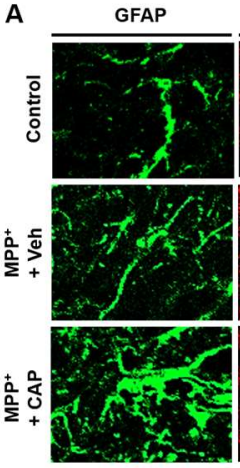

C

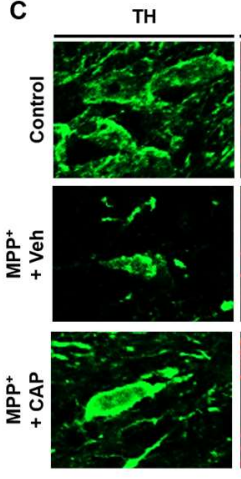

E

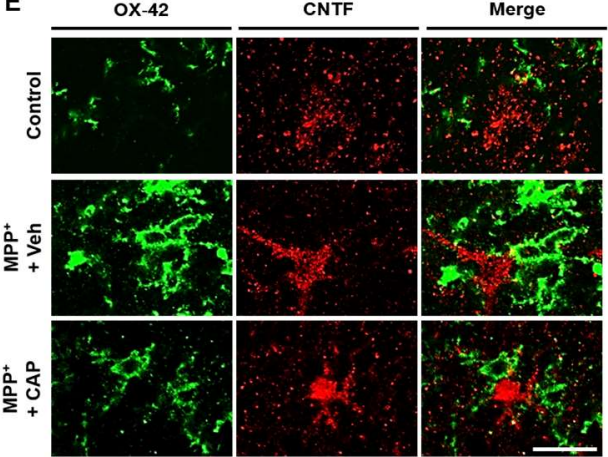

Merge

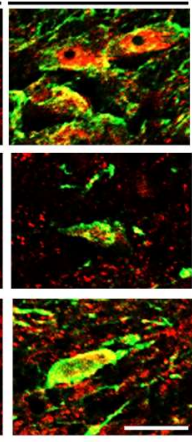

B

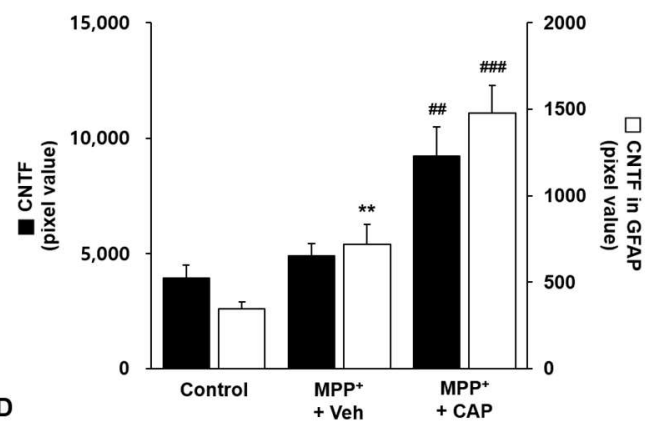

$\mathbf{F}$
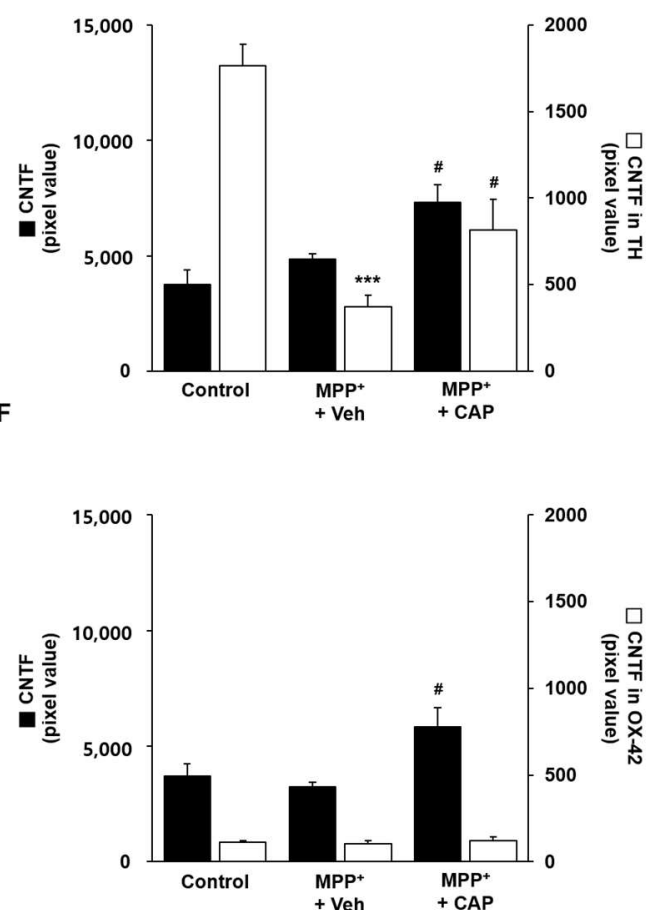

Figure 3. $\mathrm{CNTF}$ expression in the $\mathrm{SN}$ in vivo of $\mathrm{MPP}^{+}$-lesioned rat. $\mathrm{MPP}^{+}$was unilaterally injected into the rat MFB followed by i.p. treatment of CAP $(1 \mathrm{mg} / \mathrm{kg})$ or Veh at 8 days post MPP ${ }^{+}$injection and a continuous single injection per day for 7 days. (A) Fluorescence images of CNTF (red; A) or GFAP ${ }^{+}$cells (green; A) and both images are merged in the rat $\mathrm{SN}$ at 2 weeks post $\mathrm{MPP}^{+}$injection. (B) Quantification of CNTF or CNTF expression in $\mathrm{GFAP}^{+}$cells. One way ANOVA $\left[\mathrm{F}_{\mathrm{CNTF}}(2,9)=12.42, p=0.0026\right.$, $\mathrm{F}_{\mathrm{CNTF}}$ in $\operatorname{GFAP}(2,11)=37.24, p<0.0001$ ] and Newman-Keuls analysis, ${ }^{* *} p<0.01$, significantly different from control. ${ }^{\#} p<0.01,{ }^{\# \#} p<0.001$, significantly different from $\mathrm{MPP}^{+}+$Veh. (C) Fluorescence images of CNTF (red; C) or $\mathrm{TH}^{+}$cells (green; C) and both images are merged in the rat SN at 2 weeks post $\mathrm{MPP}^{+}$injection. (D) Quantification of CNTF or CNTF expression in $\mathrm{TH}^{+}$cells. One way ANOVA $\left[\mathrm{F}_{\mathrm{CNTF}}(2,15)=8.675, p=0.0031, \mathrm{~F}_{\mathrm{CNTF}}\right.$ in $\left.\mathrm{TH}(2,14)=27.53, p<0.0001\right]$ and Newman-Keuls analysis, *** $p<0.001$, significantly different from control. ${ }^{\#} p<0.05$, significantly different from $\mathrm{MPP}^{+}+$Veh. (E) Fluorescence images of CNTF (red; E) or OX-42+ cells (green; E) and both images are merged in the rat $\mathrm{SN}$ at 2 weeks post $\mathrm{MPP}^{+}$injection. (F) Quantification of $\mathrm{CNTF}$ or CNTF expression in OX-42 ${ }^{+}$ cells. One way ANOVA $\left[\mathrm{F}_{\mathrm{CNTF}}(2,10)=5.246, p=0.0277\right]$ and Newman-Keuls analysis, ${ }^{\#} p<0.05$, significantly different from $\mathrm{MPP}^{+}+$Veh. Scale bars; $20 \mu \mathrm{m}$. Mean \pm S.E.M.; (B) $n=3$ to 7; (D) $n=5$ to 7; (F) $n=4$ to 6 . 
A

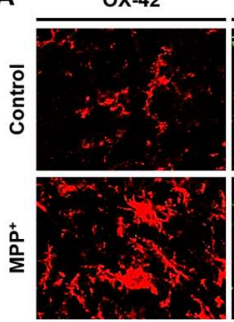

D

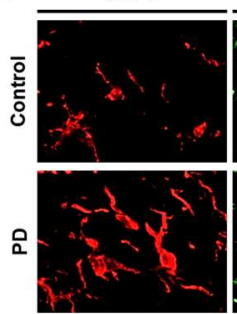

CNTFRa

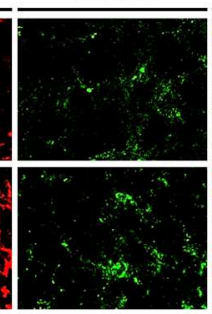

CNTFRa

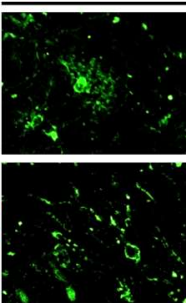

Merge

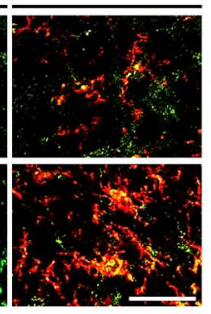

Merge

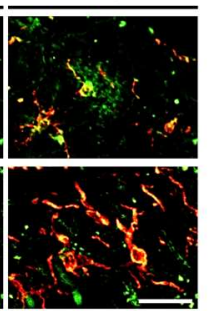

B

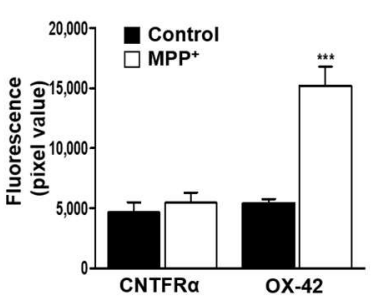

E

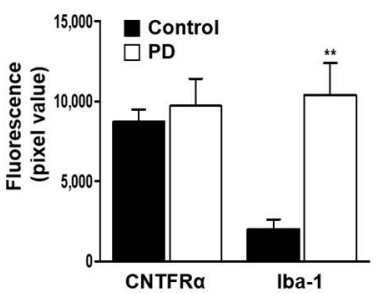

C

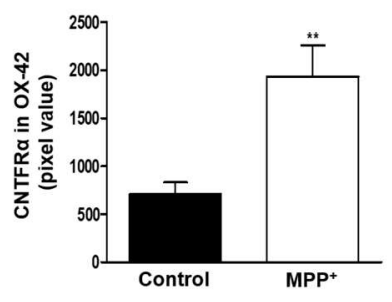

$\mathbf{F}$

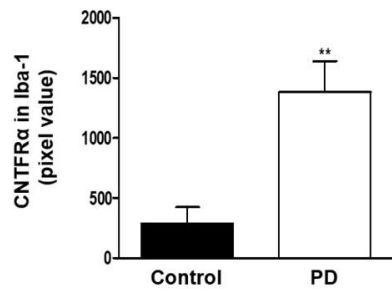

Figure 4. CNTFR $\alpha$ expression on microglia in the $\mathrm{SN}$ of the $\mathrm{MPP}^{+}$-lesioned rat and human PD brain. (A-C) $\mathrm{MPP}^{+}$was unilaterally injected into the rat MFB and tissues were prepared for immunohistochemical analysis at 1 week post $\mathrm{MPP}^{+}$injection. (A) Fluorescence images of CNTFR $\alpha$ (green) or OX-42 (red) and both images are merged in the rat SN 1 week post $\mathrm{MPP}^{+}$injection into rat MFB. Quantification of CNTFR $\alpha$ expression and OX- $42^{+}$cells (B), and CNTFR $\alpha$ expression in OX-42 ${ }^{+}$ cells $\left(\right.$ C). Student $t$-Test analysis, ${ }^{* *} p<0.01\left(t_{\text {OX- } 42}=3.513, \mathrm{df}=8\right),{ }^{* * *} p<0.001\left(t_{\text {CNTFR }} \alpha\right.$ in OX-42 $=6.115$, $\mathrm{df}=8$ ) significantly different from control. (D-F) CNTFR $\alpha$ expression in the SN of human PD brain. (D) Fluorescence images of CNTFR $\alpha$ (green) and Iba- $1^{+}$microglia (red) and both images are merged. Quantification of CNTFR $\alpha$ or Iba- $1^{+}$microglia (E), and CNTFR $\alpha$ expression in Iba- $1^{+}$microglia (F). Student $t$-Test analysis, ${ }^{* *} p<0.01\left(t_{\mathrm{Iba}-1}=3.971, \mathrm{df}=4\right),{ }^{* *} p<0.01\left(t_{\mathrm{CNTFR} \alpha \text { in Iba- } 1}=3.785, \mathrm{df}=4\right)$, significantly different from control. Scale bars; $50 \mu \mathrm{m}$ (A), $20 \mu \mathrm{m}$ (D). Mean \pm S.E.M; (B,C) $n=5$; $(\mathbf{E}, \mathbf{F}) n=3$.

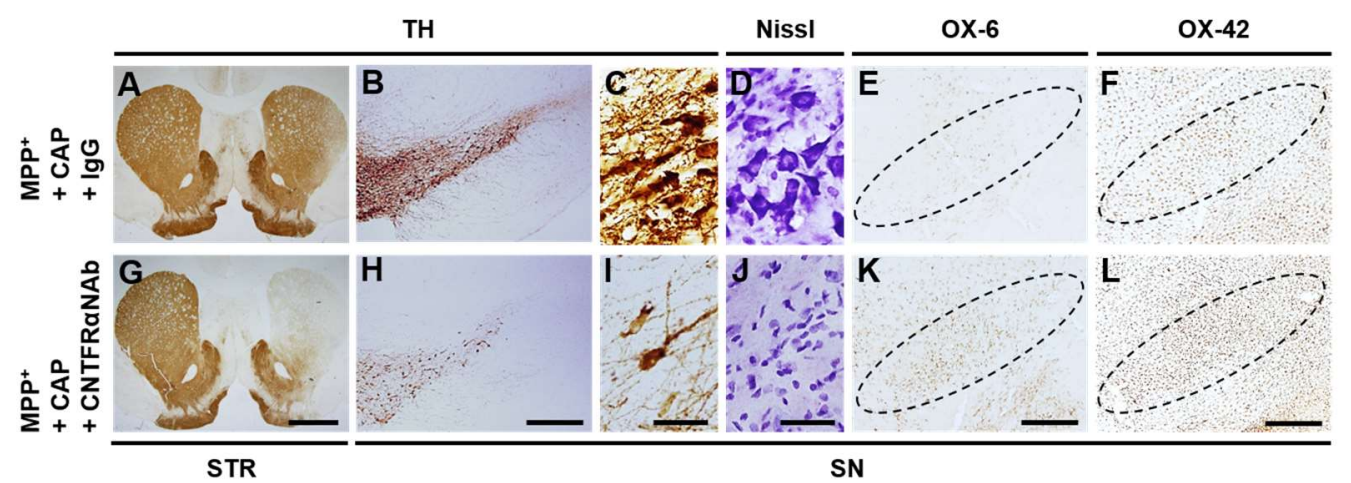

Figure 5. Cont. 


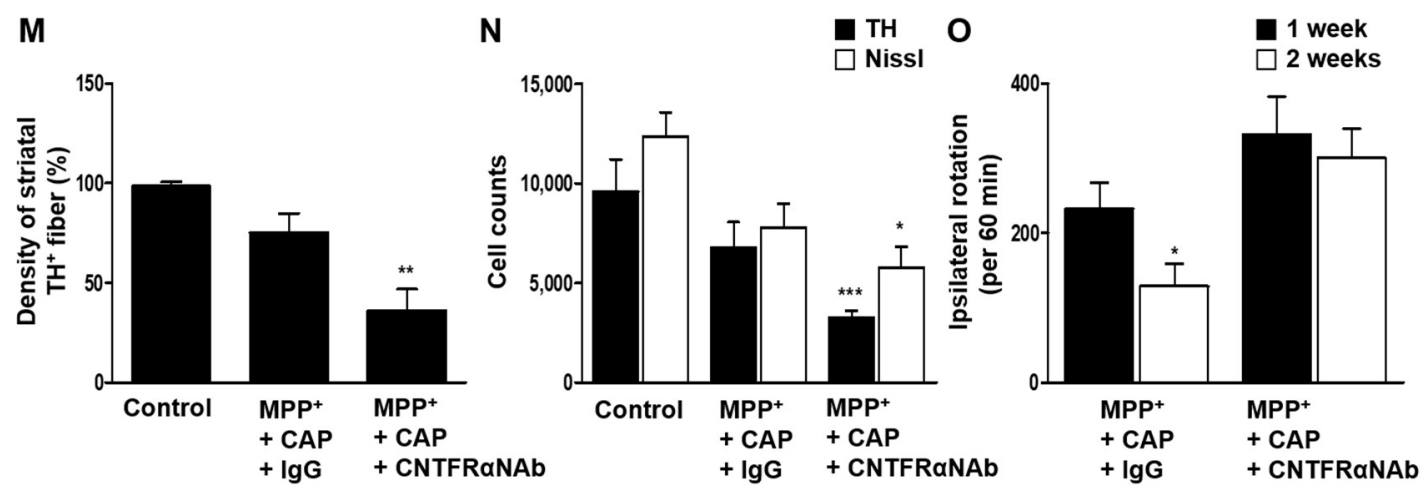

Figure 5. Effects of CNTFR $\alpha$ on neuro-protection and microglial activation in the SN in vivo in $\mathrm{MPP}^{+}$-lesioned rat. $\mathrm{MPP}^{+}$was unilaterally injected into the rat MFB followed by intranigral injection of CNTFR $\alpha$ neutralizing antibody (CNTFR $\alpha$ NAb) or IgG (control) at 1 week post $\mathrm{MPP}^{+}$injection. All rats i.p. received CAP at 8 days post $\mathrm{MPP}^{+}$and a continuous single injection per day for 7 days. Rats were transcardially perfused after the last amphetamine-induced rotation experiment. (A-L) Photomicrographs of $\mathrm{TH}^{+}$fibers $(\mathbf{A}, \mathbf{G})$ in the STR, and $\mathrm{TH}^{+}(\mathbf{B}, \mathbf{C}, \mathbf{H}, \mathbf{I}), \mathrm{Niss}^{+}(\mathbf{D}, \mathbf{J}), \mathrm{OX}_{-} 6^{+}(\mathbf{E}, \mathbf{K})$ and $\mathrm{OX}-42^{+}(\mathbf{F}, \mathbf{L})$ cells in the SN. (M) Optical density of striatal $\mathrm{TH}^{+}$fibers. Student $t$-Test analysis, ** $p<0.01(t=2.720, \mathrm{df}=15)$, significantly different from $\mathrm{MPP}^{+}+\mathrm{CAP}+\mathrm{IgG}$. (N) Number of $\mathrm{TH}^{+}$ or $\mathrm{Nissl}^{+}$cells in the SN. Student $t$-Test analysis, ${ }^{*} p<0.05(t=1.883, \mathrm{df}=10),{ }^{* * *} p<0.001(t=4.355$, $\mathrm{df}=10)$, significantly different from $\mathrm{MPP}^{+}+\mathrm{CAP}+\mathrm{IgG} .(\mathbf{O})$ Cumulative amphetamine-induced ipsilateral rotations. Student $t$-Test analysis, ${ }^{*} p<0.05(t=2.239, \mathrm{df}=24)$, significantly different from 1 week. Dotted lines indicate SN. Scale bars: $1 \mathrm{~mm}(\mathbf{A}, \mathbf{G}), 400 \mu \mathrm{m}(\mathbf{B}, \mathbf{E}, \mathbf{F}, \mathbf{H}, \mathbf{K}, \mathbf{L}), 40 \mu \mathrm{m}(\mathbf{C}, \mathbf{D}, \mathbf{I}, \mathbf{J})$. Mean \pm S.E.M; (M) $n=8$ to $9 ;(\mathbf{N}) n=5$ to $7 ;(\mathbf{O}) n=10$ to 13 .

2.5. CNTF Derived from TRPV1 Activated Astrocytes Inhibits Microglial ROS Production in the SN In Vivo in $M P P^{+}$-Lesioned Rat

Activated microglia generates ROS, which may impose oxidative stress on DA neurons in the SN of PD animal models [38,39] and in the SN of patients with PD [3,4,7], leading to DA neuronal cell death. As CNTF seems to exert its neuro-protection through inhibiting microglial activation, we hypothesized that CNTF could inhibit activated microglia-derived ROS production via CNTFR $\alpha$ on microglia. To test this, hydro-ethidine histochemistry was performed for in situ visualization of $\mathrm{O}_{2}{ }^{-}$production. $\mathrm{MPP}^{+}$significantly increased $\mathrm{O}_{2}{ }^{-}$production (visualized as the fluorescent product of oxidized hydroethidine, i.e., ethidium accumulation) compared to control (Figure 6A). Microglia-derived $\mathrm{O}_{2}{ }^{-}$production was then visualized using double immunofluorescence staining, which showed co-localization of hydroethidine staining within $\mathrm{OX}-42^{+}$cells (Figure 6B). In the CAP-treated $\mathrm{MPP}^{+}$-lesioned rats, shTRPV1 significantly increased $\mathrm{O}_{2}{ }^{-}$production in microglia of the SN (Figure 6A,C,D), compared with shCtrl-injected control rats at 2 weeks post $\mathrm{MPP}^{+}$ injection. The CAP-induced reduction of $\mathrm{O}_{2}{ }^{-}$production in microglia was significantly decreased in the $\mathrm{SN}$ of $\mathrm{MPP}^{+}$-lesioned rats treated with $\mathrm{CNTFR} \alpha \mathrm{NAb}$ compared with non-specific IgG as a control (Figure 6A,C,D). Taken together, these results indicate that CNTF derived from TRPV1 activated astrocytes inhibits microglial ROS production through CNTFR $\alpha$ on microglia in the SN of $\mathrm{MPP}^{+}$-lesioned rat. 


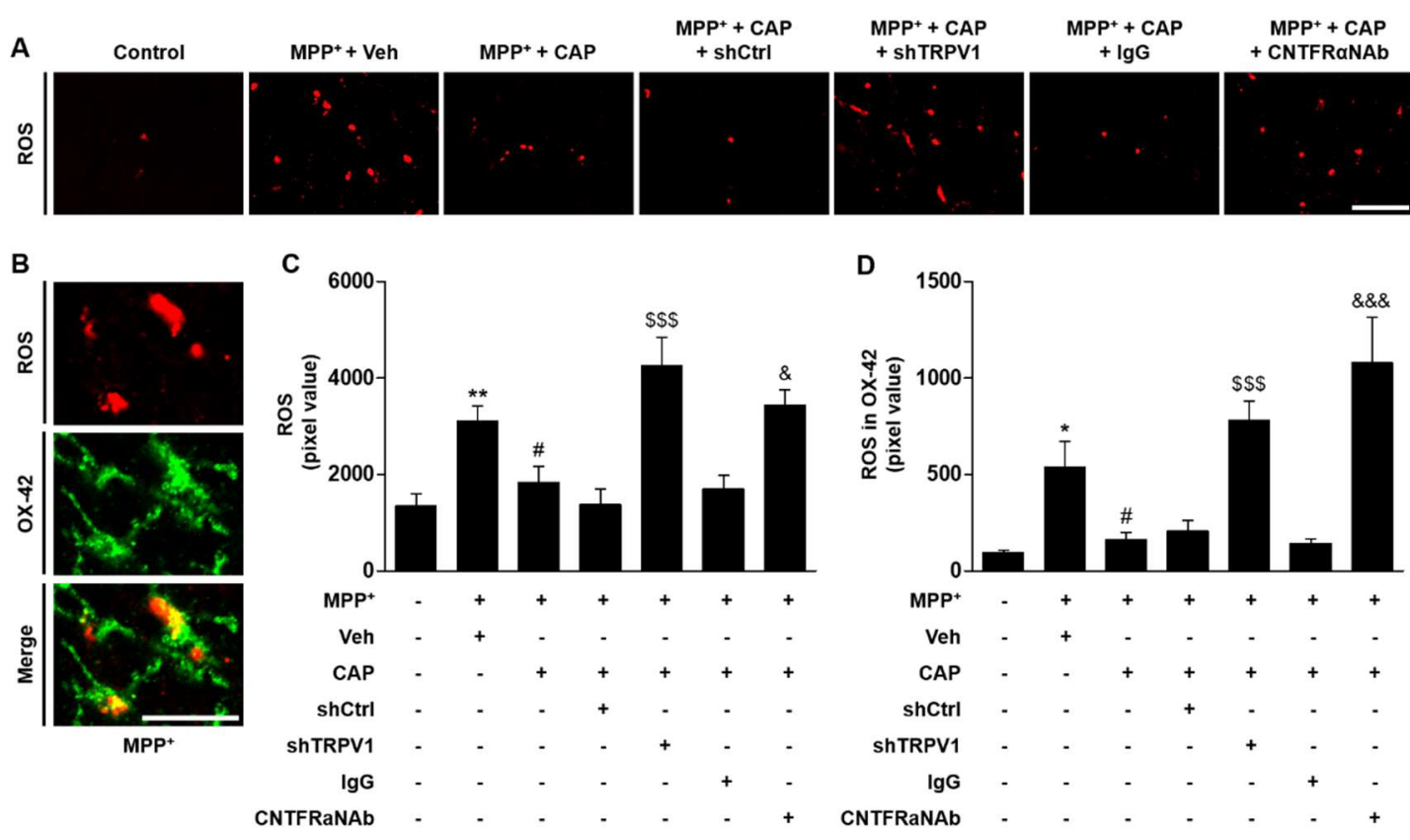

Figure 6. CNTF originated from TRPV1 activated astrocytes inhibits microglia-derived oxidative stress in the $\mathrm{SN}$ in vivo in $\mathrm{MPP}^{+}$-lesioned rat. At 2 weeks post $\mathrm{MPP}^{+}$injection with indicated treatment, hydroethidine was administered through tail vein. After $45 \mathrm{~min}$, the rats were transcardially perfused and immunohistochemical analyzed. (A) Fluorescence images of ROS (red, ethidium fluorescence) in the SN. (B) Fluorescence images of ROS (red) or OX-42 (green) and both images are merged (yellow) in the rat $\mathrm{SN}$ at 1 week post $\mathrm{MPP}^{+}$injection. Quantification of ROS expression $(\mathrm{C})$, and ROS expression in OX-42 ${ }^{+}$cells (D). One way ANOVA $\left[F_{\text {ROS }}(6,43)=9.608, p<0.0001 ; F_{R O S}\right.$ in OX-42 $\left.(6,38)=13.67, p<0.0001\right]$ and Newman-Keuls analysis, ${ }^{*} p<0.05,{ }^{* *} p<0.01$, significantly different from control; ${ }^{*} p<0.05$, significantly different from $\mathrm{MPP}^{+}+\mathrm{Veh} ;{ }^{\$ \$} p<0.001$, significantly $\mathrm{MPP}^{+}+\mathrm{CAP}+$ shCtrl; \& $p<0.05$, $\& \& \& p<0.001$, significantly different from $\mathrm{MPP}^{+}+\mathrm{CAP}+$ IgG. Scale bars: $40 \mu \mathrm{m}(\mathbf{A}), 20 \mu \mathrm{m}(\mathbf{B})$, Mean \pm S.E.M.; (C) $n=5$ to 9 ; (D) $n=5$ to 8 .

\section{Discussion}

The present study demonstrates that CNTF originated from TRPV1 activated astrocytes inhibits microglial activation and activated microglia-derived oxidative stress through CNTFR $\alpha$ on microglia and rescues DA neurons in the $\mathrm{SN}$ of $\mathrm{MPP}^{+}$-lesioned rats, an animal model of $\mathrm{PD}$ (Figure 7). Intriguingly, compared to control, microglia show no change in expression of endogenous CNTF with a significant increase in CNTFR $\alpha$ in $\mathrm{MPP}^{+}$-lesioned rat $\mathrm{SN}$ in vivo. Immunohistochemical analysis revealed a significant increase in levels of CNTFR $\alpha$ expression on microglia in postmortem SN tissue from humans with $\mathrm{PD}$, indicating that these findings may have relevance to this disease.

Many studies on PD pathology suggest that glial activation along with neuro-inflammatory processes, like microglial activation, astrogliosis and infiltrated immune cells, contribute to the initiation or progression of PD [38]. DA neurons in the SN are particularly susceptible to oxidative stress because of severe depletion of antioxidants by accumulation of iron and ageing [40-42]. Activated microglia generates ROS, which may impose oxidative stress on DA neurons in the $\mathrm{SN}$ of both patients with $\mathrm{PD}[3,4,7]$ and $\mathrm{MPP}^{+}$-lesioned rats [9], leading to DA neuronal cell death. We recently reported that CAP contributes to DA neuronal survival by inhibiting microglia-derived oxidative stress in the $\mathrm{SN}$ of $\mathrm{MPP}^{+}$-lesioned rats [9]. This study also showed that CAP neuro-protection was masked by pharmacological inhibition of TRPV1 with capsazepine, an antagonist of TRPV1, suggesting TRPV1 involvement. This hypothesis was further confirmed and strongly supported by the present data showing that the CAP-induced neuro-protection and behavioral recovery attained through inhibiting microglia-derived oxidative stress are abolished by genetic knockdown of TRPV1 with shTRPV1 [13]. Consistent with our recent report [13], the present study demonstrated selective inhibition of astrocytic 
TRPV1 function by shTRPV1, indicating that astrocytic TRPV1 activation, in particular, contributes to inhibiting microglia-derived oxidative stress in the $\mathrm{SN}$ of $\mathrm{MPP}^{+}$-lesioned rats.

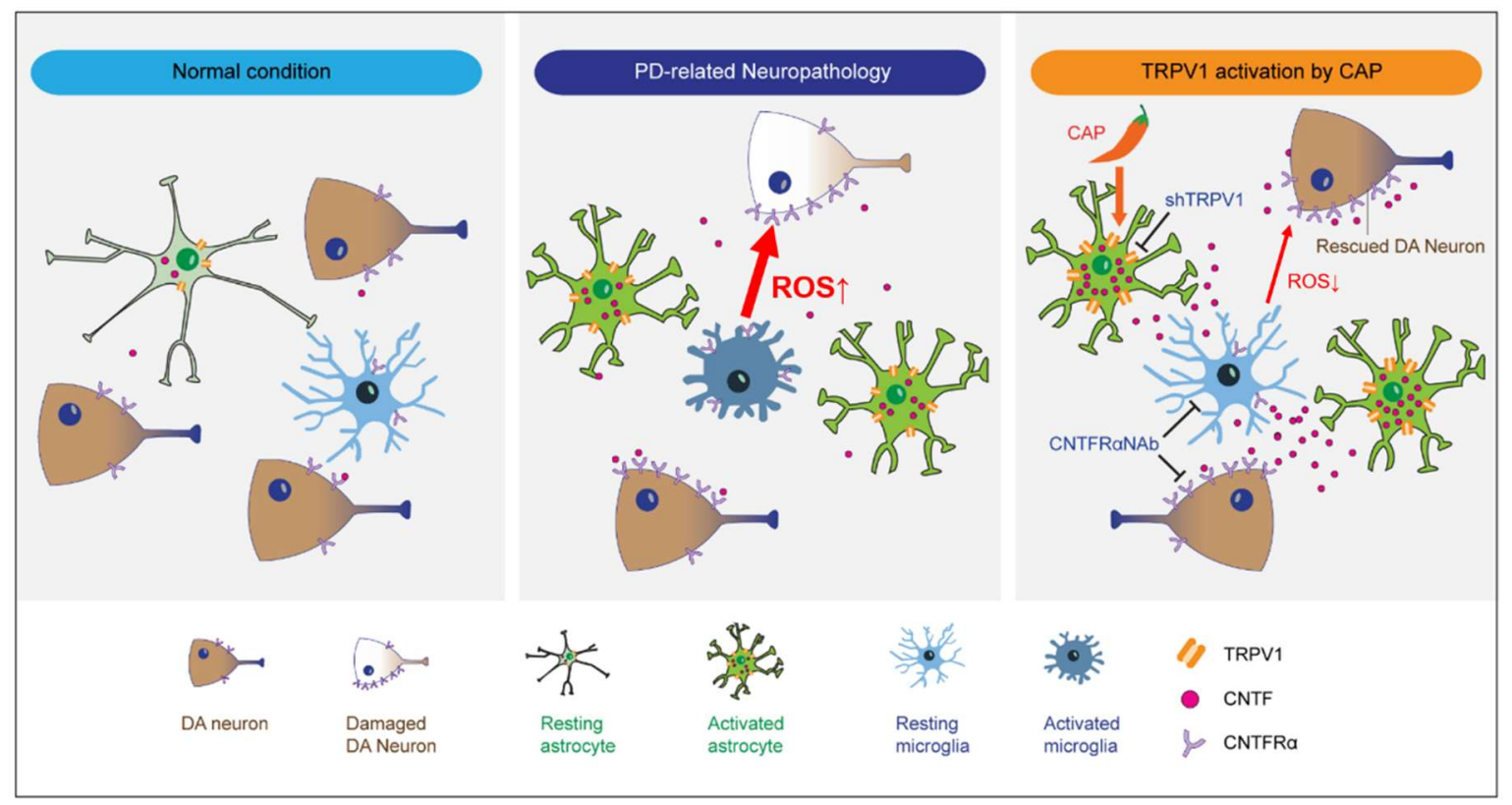

Figure 7. Microglial ROS production is attenuated by astrocytic TRPV1-derived CNTF, resulting in survival of nigral dopamine neurons in Parkinson's disease. There is a dramatic expression of CNTFR $\alpha$ in reactive microglia in the substantia nigra pars compacta (SNpc) of human Parkinson's disease and Parkinson's disease-related neuropathology, compared to the respective controls. Note that astrocytic TRPV1-derived CNTF by CAP inhibits microglial ROS production through CNTFR $\alpha$ on microglia and rescues dopamine neurons in the SNpc of Parkinson's disease in vivo. TRPV1, Transient Receptor Potential Vanilloid 1; shTRPV1, TRPV1 shRNA lentivirus; DA, Dopamine; CNTF, Ciliary Neurotrophic Factor; CNTFR $\alpha, C N T F$ receptor alpha; CNTFR $\alpha$ NAb, CNTF receptor alpha neutralizing antibody; CAP, capsaicin.

CNTF, expressed in astrocytes upon brain injury [21,43,44] has neuro-protective properties [37], inhibiting microglial activation [29], microglia-derived oxidative stress [25] or both. Consistent with our recent data $[9,13], \mathrm{CNTF}$ was expressed on astrocytes in the SN of $\mathrm{MPP}^{+}$-lesioned rats and treatment with CNTFR $\alpha$ NAb reduced CAP-induced neuro-protection. Accompanying the lack of neuro-protection was a reduction of CAP effects on microglia-derived oxidative stress, suggesting the inhibitory effects of astrocytic CNTF on microglial activation.

Although our data point to the beneficial effects of CNTF, originating from astrocytes, in particular, the possibility remains that CAP-induced TRPV1 activation produces microglia-originated CNTF, resulting in neuro-protection and inhibition of microglial activation-mediated oxidative stress. This hypothesis is supported by several lines of evidence showing that TRPV1 is expressed on microglia [45], particularly in the SN of $\mathrm{MPP}^{+}$-lesioned rats [13] and that microglia produces CNTF following several types of stimulation, including light-induced retinal degeneration [22] and cuprizone-induced demyelination [23]. However, our immunohistochemical analysis revealed little CNTF expression in the SN microglia of $\mathrm{MPP}^{+}$-lesioned rats with or without CAP administration. It is therefore likely that CNTF is primarily expressed in astrocytes, but not in microglia under our experimental conditions.

Although CNTF appeared to exert neuro-protection via CNTFR $\alpha$ located on DA neurons [13], several in vitro studies have shown CNTFR $\alpha$ expression on microglia $[25,33]$. The present study demonstrated a substantial expression of CNTFR $\alpha$ on microglia in the SN of MPP ${ }^{+}$-lesioned rats and a CNTFR $\alpha$ NAb-induced reduction in CAP effects, suggesting that CNTFR $\alpha$ located on microglia could be involved in neuronal survival through inhibition of microglial activation. This microglial CNTFR $\alpha$-mediated effect would be in addition or parallel to CNTF actions on DA neurons. This 
observation appears to be important under pathological conditions, given that microglia-derived oxidative stress plays a pivotal role in the initiation of $\mathrm{PD}$, its progression, or both. Therefore, it is likely that CNTF derived from CAP-induced astrocytic TRPV1 activation can act as an endogenous neurotrophic factor, contributing both directly and indirectly to DA neuronal survival in the $\mathrm{MPP}^{+}$rat model of PD.

We have recently shown that CNTFR $\alpha$ was expressed in $\mathrm{TH}^{+}$cells in the $\mathrm{SN}$ of intact rat, and CNTFR $\alpha$ expression in $\mathrm{TH}^{+}$cells was significantly decreased in the $\mathrm{SN}$ of $\mathrm{MPP}^{+}$-lesioned rat without change of total CNTFR $\alpha$ expression [13]. Regarding this, in the present study, the total expression of CNTFR $\alpha$ is not changed, whereas there is significantly increased CNTFR $\alpha$ expression within OX-42 ${ }^{+}$ cells in the SN of $\mathrm{MPP}^{+}$-lesioned rat. Accordingly, increased level of CNTFR $\alpha$ expression in OX-42 $2^{+}$ cells may reflect decreased levels of CNTFR $\alpha$ expression in $\mathrm{TH}^{+}$cells in the $\mathrm{SN}$ of $\mathrm{MPP}^{+}$-lesioned rat.

Taken together with our recent data (TRPV1 and CNTF expression on astrocytes, and CNTFR $\alpha$ expression on DA neurons) [13], CNTFR $\alpha$ expression on microglia in the SN of both humans with PD and $\mathrm{MPP}^{+}$-lesioned rats suggests that endogenous CNTF derived from TRPV1 activated astrocytes has therapeutic potential to restore motor function in the treatment of PD by inhibiting activated microglia-mediated oxidative stress and/or preventing the progressive degeneration of DA neurons.

\section{Materials and Methods}

\subsection{Animals}

All experiments were done in accordance with Institutional Animal Care and Use Committee of Kyunghee University and to minimize number of animal experiments and suffering, we carried out the experiment with strict observance of the protocols and guidelines established by Kyung Hee University (KHUASP (SE)-16-059, 8 August 2016). Female Sprague-Dawley rats (10 weeks of age, 240-270 g, purchased from Daehan Biolink, introduced from Taconic Co., Albany, NY, USA) were housed under a 12:12 h light: dark cycle at an ambient temperature of $22{ }^{\circ} \mathrm{C}$. Water and rat chow were available ad libitum.

\subsection{Human Samples}

Human brain tissues (age-matched control and Parkinson's disease subjects obtained from the Victoria Brain Bank Network (VBBN), Table 1) were prepared to immunohistochemical staining [13]. Human tissue experiments were done in accordance with the Institutional Review Board of Kyung Hee University Hospital (KMC IRB 1234-04, 30 November 2012).

\subsection{Stereotaxic Surgery and Tissue Preparation}

Stereotaxic surgery under chloral hydrate was performed as described [13]. Using coordinates relative to the bregma, stereotaxic injections of $\mathrm{MPP}^{+}$(right medial forebrain bundle (MFB); A/P -3.6, ML -2.0, DV -7.5; $\mathrm{MPP}^{+}, 7.4 \mu \mathrm{g}$ in $2 \mu \mathrm{L}$ phosphate-buffered saline (PBS), Sigma, St. Louis, MO, USA), lentivirus (right SN; A/P -5.3, ML -2.3, DV -7.6; shTRPV1, shCtrl; $0.2 \mu \mathrm{L} / \mathrm{min}$, total $3 \mu \mathrm{L}$ ), CNTFR $\alpha \mathrm{NAb}$ (right SN; A/P -5.3, M/L -2.3, D/V -7.6; R\&D, AF-303-NA; $0.01 \mathrm{mg} / \mathrm{mL}, 0.2 \mu \mathrm{L} / \mathrm{min}$, total $2 \mu \mathrm{L}$ ) and respective control were done according to the atlas of Paxinos and Watson [46]. Lentivirus was injected immediately after MPP ${ }^{+}$injection. CNTFR $\alpha$ NAb was injected at 1 week post $\mathrm{MPP}^{+}$injection. As described [47], animals were anesthetized with chloral hydrate $(360 \mathrm{mg} / \mathrm{kg}$, i.p. injection) at the indicated time points after injection and transcardially perfused and fixed with $4 \%$ paraformaldehyde dissolved in $0.1 \mathrm{M}$ phosphate buffer (PB). Brains were removed from the skull, post fixed overnight at $4{ }^{\circ} \mathrm{C}$ in buffered $4 \%$ paraformaldehyde, and stored at $4{ }^{\circ} \mathrm{C}$ in $30 \%$ sucrose solution until they sank. Brains were frozen sectioned using a sliding microtome into $40 \mu \mathrm{m}$ coronal sections and collected in six separate series of $\mathrm{SN}$ and striatum. 


\subsection{Capsaicin (CAP) Injection}

Before choosing route and dose of CAP injection used here, we measured behavioral changes to avoid painful activation (behavior) of peripheral TRPV1-containing neurons (Table 2). All rats intraperitoneally received a single injection of capsaicin $(1,5$, and $10 \mathrm{mg} / \mathrm{kg})$ per day for 7 days. Based on behavioral symptoms and previous results [13,48], CAP $(1 \mathrm{mg} / \mathrm{kg}$, i.p. injection; a single injection/day for 7 days, Sigma) was injected at 1 week and 1 day post $\mathrm{MPP}^{+}$injection.

Table 2. Results of capsaicin dose effect test in lethality, pain degree and behavioral symptoms.

\begin{tabular}{|c|c|c|c|c|c|}
\hline \multirow{2}{*}{$\begin{array}{c}\text { Capsaicin } \\
\text { Dose }(\mathrm{mg} / \mathrm{kg})\end{array}$} & \multicolumn{3}{|c|}{ Lethality } & \multirow{2}{*}{ Pain Degree } & \multirow{2}{*}{$\begin{array}{c}\text { Behavioral Symptoms } \\
\text { (Paroxysm, Spasticity, Couching) }\end{array}$} \\
\hline & Dead & Total & $\%$ & & \\
\hline $1 \mathrm{mg} / \mathrm{kg}$ & 0 & 18 & 0 & + & $\begin{array}{l}\text { Last for } 1-2 \mathrm{~min} \text { after capsaicin injection only at } \\
1 \text { st day }\end{array}$ \\
\hline $5 \mathrm{mg} / \mathrm{kg}$ & 1 & 15 & 6.6 & ++ & $\begin{array}{l}\text { Last for } 5-10 \mathrm{~min} \text { after capsaicin injection for } \\
7 \text { days }\end{array}$ \\
\hline $10 \mathrm{mg} / \mathrm{kg}$ & 9 & 15 & 60 & +++ & $\begin{array}{l}\text { Last for more than } 10 \text { min after capsaicin } \\
\text { injection for } 7 \text { days } \\
\text { Some of rat }(N=9) \text { was dead in less than } 1 \text { min }\end{array}$ \\
\hline
\end{tabular}

+ , slight response; ++ , medium response; +++ , strong response.

\subsection{Rotational Behavior Test}

As described [13], D-Amphetamine (5 mg/ $\mathrm{kg}$, i.p. injection) was used to monitor ipsilateral rotation in rats with unilaterally $\mathrm{MPP}^{+}$administration. Rats that exhibited ipsilateral rotations, indicative of an effective lesion were randomly selected for treatment with the CAP $(1 \mathrm{mg} / \mathrm{kg}$, i.p. injection) or vehicle each day for 7 days. The ipsilateral rotations were counted for $1 \mathrm{~h}$. Rats were transcardially perfused for immunostaining at $30 \mathrm{~min}$ after the last rotation experiment.

\subsection{Stereological Estimation}

As described [13], the total number of $\mathrm{TH}^{+}$neurons were counted in the various animal groups using the optical fractionator method performed on a bright field microscope (Olympus Optical, BX51, Tokyo, Japan) using Stereo Investigator software (MBF Bioscience, Williston, VT, USA). This unbiased stereological method of cell counting is not affected by either the reference volume $\mathrm{SN}$ or the size of the counted elements (neurons). According to Paxinos and Watson [46], all assessments were analyzed in six separated sections in the front and the rear of each target area. As described previously [47], the quantification area for $\mathrm{SN}$ are $-4.56 \mathrm{~mm}$ to $-6.60 \mathrm{~mm}$ from bregma in the total area.

\subsection{Morphological Analysis}

Optical densities of the $\mathrm{TH}^{+}$striatal fibers were measured using Science Lab 2001 Image Gauge (Fujifilm, Tokyo, Japan) [13]. According to Paxinos and Watson [46], all assessments were analyzed in six separated sections in the front and the rear of each target area. The quantification areas for striatal fibers are $+2.16 \mathrm{~mm}$ to $+0.12 \mathrm{~mm}$ from bregma in the total area.

\subsection{Image J Analysis}

Imaging data were analyzed in Image J (National Institutes of Health) as described recently [13]. Image J with co-localization plugin was used to quantify immunofluorescence and with color deconvolution plugin was used to quantify chromogenic signal intensity on image.

\subsection{Immunostaining}

As described [13], rat brain tissues were prepared for immunohistochemical staining. In brief, brain sections ( 3 tissues per each animal) were rinsed and then incubated with the following primary antibodies: rabbit anti-TRPV1 (1:1000, Alomone labs, Jerusalem, Israel), rabbit anti-CNTF (1:200, 
Santa-Cruz), goat-anti-CNTFR $\alpha$ (1:200, Santa Cruz, Santa Cruz, CA, USA), mouse and rabbit anti-GFAP (1:500, mouse, Sigma, St. Louis, MO, USA; 1:5000, rabbit, Neuromics, Edina, MS, USA) for astrocytes, rabbit anti-tyrosine hydroxylase (TH, 1:2000, rabbit, Pel-Freez, Rogers, AR, USA) for dopamine neurons and mouse anti-OX-6 (1:400, BD Pharmingen, San Jose, CA, USA), mouse anti-OX-42 (1:400, mouse, BIO-RAD, Hercules, CA, USA) and anti-lba-1 (1:1000, rabbit, Wako, Richmond, VA, USA) for microglia. Stained tissues were viewed using a confocal microscopy (LSM700, Carl Zeiss, Oberkochen, Germany) or were analyzed under a bright-field microscope (Olympus, Tokyo, Japan). For Human brain experiments, brain sections were deparaffinized, subjected to citrate antigen retrieval prior to immunohistochemistry, washed in cold phosphate-buffered saline (PBS) and block with universal blocking solution at room temperature. Primary antibodies of Iba-1 (1:1000, rabbit, Wako, Richmond, VA, USA), CNTFR $\alpha$ (1:200, goat, Santa Cruz, Santa Cruz, CA, USA) were diluted in $1-5 \%$ BSA or normal goat serum and incubated according to manufacturer recommendations. For fluorescent microscopy, brain tissues were labeled using FITC-conjugated-anti-mouse or goat (1:400, Millipore, Burlington, MA, USA), Cy3-conjugated-anti-mouse (1:400, Millipore, Burlington, MA, USA), CF405M-conjugated-anti-mouse IgG (1:400, Biotium, Fremont, CA, USA) and Texas Red-conjugated-anti-rabbit (1:400, Vector Laboratories, Burlingame, CA, USA) secondary antibodies with 4',6-diamidino-2-phenylindole (DAPI) nuclear counterstain (Vector Laboratories, Burlingame, CA, USA). After washing with PBS, coverslips were mounted on glass slides using mounting media (Vector Laboratories), and analyzed using a confocal microscope (LSM700, Carl Zeiss, Oberkochen, Germany).

\subsection{TRPV1 shRNA and Lentivirus Production}

As described [13], for plasmid-based short hairpin (sh) RNA expression, the following complementary oligonucleotides were annealed and inserted into the HindIII/BgIII sites of pSUPER-EGFP vector: gcgcatcttctacttcaac (sense) TTAGCACTG (loop) gttgaagtagaagatgcgc (antisense), corresponding to nucleotide sequence of TRPV1 [49]. For lentivirus-based shRNA expression, a lentiviral vector containing TRPV1 gene was constructed by inserting synthetic double-strand oligonucleotides 5'-CGCTGCAGTTGCCAACTTGTCAATGAATTCAAGAGATTCATTGACAAGTT GGCAATTTTTGATATCTAGACA- $3^{\prime}$ into the HpaI-XhoI restriction enzyme sites of the pSicoR-mcherry lentiviral vector. A shLenti construct containing scrambled oligonucleotides: 5'-CGCATAGCGTATGCCGTTTTCAAGAGAAACGGCATACGCTATGCGATTTTTTC-3' was used as a control.

\subsection{In Situ Detection of $\mathrm{O}_{2}{ }^{-}$and $\mathrm{O}_{2}{ }^{-}$-Derived Oxidants}

As previously described [9], hydroethidine histochemistry was performed for in situ visualization of $\mathrm{O}_{2}{ }^{-}$and $\mathrm{O}_{2}{ }^{-}$-derived oxidants. At 2 weeks post $\mathrm{MPP}^{+}$injection, hydroethidine $(1 \mathrm{mg} / \mathrm{mL}$ in PBS containing 1\% dimethyl sulfoxide; Sigma) was administered through tail vein. After $45 \mathrm{~min}$, the animals were transcardially perfused, fixed and brain tissues ( $40 \mu \mathrm{m}$ thickness) were mounted on gelatin-coated slides. The oxidized hydroethidine product, ethidium, examined by confocal microscopy and merged with OX-42 antibody for double-immunofluorescence staining.

\subsection{Statistical Analysis}

All values are expressed as mean standard error of the mean. Statistical significance $(p<0.05$ for all analysis) was assessed by One way ANOVA Newman-Keuls analyses and Student unpaired $t$-test (GraphPad Software, San Diego, CA, USA). F values were provided in each figure legends.

Supplementary Materials: Supplementary materials can be found at http:/ / www.mdpi.com/1422-0067/19/11/ 3543/s1.

Author Contributions: Conceptualization, W.-H.S. and B.K.J.; Data curation, J.Y.B., J.Y.J., K.I.K., W.-H.S. and B.K.J.; Formal analysis, J.Y.B., J.Y.J. and K.I.K.; Funding acquisition, B.K.J.; Resources, T.-B.A.; Supervision, W.-H.S. and B.K.J.; Validation, S.-Y.W., Y.C.C., J.H.N., E.J.C., T.-B.A. and E.B.; Writing-original draft, J.Y.B., J.Y.J., K.I.K., W.-H.S. and B.K.J. 
Funding: This research was funded by the National Research Foundation of Korea (NRF) grant by the Korean Government NRF-2016R1A2B4010692, NRFM3C7A1031105 and NRF-2018R1A6A1A03025124.

Acknowledgments: Human brain Tissues were received from the Victorian Brain Bank Network, supported by The Florey Institute of Neuroscience and Mental Health, The Alfred and the Victorian Forensic Institute of Medicine and funded in part by Australia's National Health \& Medical Research Council and Parkinson's Victoria.

Conflicts of Interest: The authors declare no conflict of interest.

\section{References}

1. Ginhoux, F.; Lim, S.; Hoeffel, G.; Low, D.; Huber, T. Origin and differentiation of microglia. Front. Cell. Neurosci. 2013, 7, 45. [CrossRef] [PubMed]

2. Dauer, W.; Przedborski, S. Parkinson's disease: Mechanisms and models. Neuron 2003, 39, 889-909. [CrossRef]

3. Savitt, J.M.; Dawson, V.L.; Dawson, T.M. Diagnosis and treatment of Parkinson disease: Molecules to medicine. J. Clin. Investig. 2006, 116, 1744-1754. [CrossRef] [PubMed]

4. Dawson, T.M.; Dawson, V.L. Molecular pathways of neurodegeneration in Parkinson's disease. Science 2003, 302, 819-822. [CrossRef] [PubMed]

5. Hirsch, E.C.; Hunot, S. Neuroinflammation in Parkinson's disease: A target for neuroprotection? Lancet Neurol. 2009, 8, 382-397. [CrossRef]

6. Gaki, G.S.; Papavassiliou, A.G. Oxidative stress-induced signaling pathways implicated in the pathogenesis of Parkinson's disease. Neuromol. Med. 2014, 16, 217-230. [CrossRef] [PubMed]

7. Block, M.L.; Zecca, L.; Hong, J.S. Microglia-mediated neurotoxicity: Uncovering the molecular mechanisms. Nat. Rev. Neurosci. 2007, 8, 57-69. [CrossRef] [PubMed]

8. Heneka, M.T.; Kummer, M.P.; Latz, E. Innate immune activation in neurodegenerative disease. Nat. Rev. Immunol. 2014, 14, 463-477. [CrossRef] [PubMed]

9. Park, E.S.; Kim, S.R.; Jin, B.K. Transient receptor potential vanilloid subtype 1 contributes to mesencephalic dopaminergic neuronal survival by inhibiting microglia-originated oxidative stress. Brain Res. Bull. 2012, 89, 92-96. [CrossRef] [PubMed]

10. Gunthorpe, M.J.; Szallasi, A. Peripheral TRPV1 receptors as targets for drug development: New molecules and mechanisms. Curr. Pharm. Des. 2008, 14, 32-41. [PubMed]

11. Starowicz, K.; Cristino, L.; Di Marzo, V. TRPV1 receptors in the central nervous system: Potential for previously unforeseen therapeutic applications. Curr. Pharm. Des. 2008, 14, 42-54. [PubMed]

12. Kauer, J.A.; Gibson, H.E. Hot flash: TRPV channels in the brain. Trends Neurosci. 2009, 32, 215-224. [CrossRef] [PubMed]

13. Nam, J.H.; Park, E.S.; Won, S.Y.; Lee, Y.A.; Kim, K.I.; Jeong, J.Y.; Baek, J.Y.; Cho, E.J.; Jin, M.; Chung, Y.C.; et al. TRPV1 on astrocytes rescues nigral dopamine neurons in Parkinson's disease via CNTF. Brain 2015, 138 Pt 12, 3610-3622. [CrossRef]

14. Shang, K.; Amna, T.; Amina, M.; Al-Musayeib, N.M.; Al-Deyab, S.S.; Hwang, I. Influence of Capsaicin on Inflammatory Cytokines Induced by Lipopolysaccharide in Myoblast Cells under In vitro Environment. Pharmacogn. Mag. 2017, 13 (Suppl. 1), S26-S32. [PubMed]

15. Guo, S.Y.; Yang, G.P.; Jiang, D.J.; Wang, F.; Song, T.; Tan, X.H.; Sun, Z.Q. Protection of capsaicin against hypoxia-reoxygenation-induced apoptosis of rat hippocampal neurons. Can. J. Physiol. Pharmacol. 2008, 86, 785-792. [CrossRef] [PubMed]

16. Bhatia, H.S.; Roelofs, N.; Muñoz, E.; Fiebich, B.L. Alleviation of Microglial Activation Induced by p38 MAPK/MK2/PGE 2 Axis by Capsaicin: Potential Involvement of other than TRPV1 Mechanism/s. Sci. Rep. 2017, 7, 116. [CrossRef] [PubMed]

17. Chen, C.W.; Lee, S.T.; Wu, W.T.; Fu, W.M.; Ho, F.M.; Lin, W.W. Signal transduction for inhibition of inducible nitric oxide synthase and cyclooxygenase-2 induction by capsaicin and related analogs in macrophages. Br. J. Pharmacol. 2003, 140, 1077-1087. [CrossRef] [PubMed]

18. Kim, C.-S.; Kawada, T.; Kim, B.-S.; Han, I.-S.; Choe, S.-Y.; Kurata, T.; Yu, R. Capsaicin exhibits anti-inflammatory property by inhibiting IkB-a degradation in LPS-stimulated peritoneal macrophages. Cell. Signal. 2003, 15, 299-306. [CrossRef] 
19. Stöckli, K.; Lillien, L.; Näher-Noé, M.; Breitfeld, G.; Hughes, R.A.; Raff, M.; Thoenen, H.; Sendtner, M. Regional distribution, developmental changes, and cellular localization of CNTF-mRNA and protein in the rat brain. J. Cell Biol. 1991, 115, 447-459. [CrossRef] [PubMed]

20. Dallner, C.; Woods, A.G.; Deller, T.; Kirsch, M.; Hofmann, H.D. CNTF and CNTF receptor alpha are constitutively expressed by astrocytes in the mouse brain. Glia 2002, 37, 374-378. [CrossRef] [PubMed]

21. Paintlia, M.K.; Paintlia, A.S.; Singh, A.K.; Singh, I. S-nitrosoglutathione induces ciliary neurotrophic factor expression in astrocytes, which has implications to protect the central nervous system under pathological conditions. J. Biol. Chem. 2013, 288, 3831-3843. [CrossRef] [PubMed]

22. Harada, T.; Harada, C.; Kohsaka, S.; Wada, E.; Yoshida, K.; Ohno, S.; Mamada, H.; Tanaka, K.; Parada, L.F.; Wada, K. Microglia-Muller glia cell interactions control neurotrophic factor production during light-induced retinal degeneration. J. Neurosci. 2002, 22, 9228-9236. [CrossRef] [PubMed]

23. Tanaka, T.; Murakami, K.; Bando, Y.; Yoshida, S. Minocycline reduces remyelination by suppressing ciliary neurotrophic factor expression after cuprizone-induced demyelination. J. Neurochem. 2013, 127, 259-270. [CrossRef] [PubMed]

24. Albrecht, P.J.; Dahl, J.P.; Stoltzfus, O.K.; Levenson, R.; Levison, S.W. Ciliary neurotrophic factor activates spinal cord astrocytes, stimulating their production and release of fibroblast growth factor-2, to increase motor neuron survival. Exp. Neurol. 2002, 173, 46-62. [CrossRef] [PubMed]

25. Krady, J.K.; Lin, H.W.; Liberto, C.M.; Basu, A.; Kremlev, S.G.; Levison, S.W. Ciliary neurotrophic factor and interleukin-6 differentially activate microglia. J. Neurosci. Res. 2008, 86, 1538-1547. [CrossRef] [PubMed]

26. Oppenheim, R.W.; Prevette, D.; Yin, Q.; Collins, F.; MacDonald, J. Control of embryonic motoneuron survival in vivo by ciliary neurotrophic factor. Science 1991, 251, 1616-1618. [CrossRef] [PubMed]

27. Mitsumoto, H.; Ikeda, K.; Klinkosz, B.; Cedarbaum, J.M.; Wong, V.; Lindsay, R.M. Arrest of motor neuron disease in wobbler mice cotreated with CNTF and BDNF. Science 1994, 265, 1107-1110. [CrossRef] [PubMed]

28. Sagot, Y.; Tan, S.; Baetge, E.; Schmalbruch, H.; Kato, A.; Aebischer, P. Polymer encapsulated cell lines genetically engineered to release ciliary neurotrophic factor can slow down progressive motor neuronopathy in the mouse. Eur. J. Neurosci. 1995, 7, 1313-1322. [CrossRef] [PubMed]

29. Martin, A.; Hofmann, H.D.; Kirsch, M. Glial reactivity in ciliary neurotrophic factor-deficient mice after optic nerve lesion. J. Neurosci. 2003, 23, 5416-5424. [CrossRef] [PubMed]

30. Pasquin, S.; Sharma, M.; Gauchat, J.F. Ciliary neurotrophic factor (CNTF): New facets of an old molecule for treating neurodegenerative and metabolic syndrome pathologies. Cytokine Growth Factor Rev. 2015, 26, 507-515. [CrossRef] [PubMed]

31. Rudge, J.S.; Li, Y.; Pasnikowski, E.M.; Mattsson, K.; Pan, L.; Yancopoulos, G.D.; Wiegand, S.J.; Lindsay, R.M.; Ip, N.Y. Neurotrophic factor receptors and their signal transduction capabilities in rat astrocytes. Eur. J. Neurosci. 1994, 6, 693-705. [CrossRef] [PubMed]

32. Lee, M.-Y.; Deller, T.; Kirsch, M.; Frotscher, M.; Hofmann, H.-D. Differential regulation of ciliary neurotrophic factor (CNTF) and CNTF receptor $\alpha$ expression in astrocytes and neurons of the fascia dentata after entorhinal cortex lesion. J. Neurosci. 1997, 17, 1137-1146. [CrossRef] [PubMed]

33. Lin, H.W.; Jain, M.R.; Li, H.; Levison, S.W. Ciliary neurotrophic factor (CNTF) plus soluble CNTF receptor alpha increases cyclooxygenase-2 expression, $\mathrm{PGE}_{2}$ release and interferon-gamma-induced $\mathrm{CD} 40$ in murine microglia. J. Neuroinflamm. 2009, 6, 7. [CrossRef] [PubMed]

34. Kahn, M.A.; Ellison, J.A.; Speight, G.J.; de Vellis, J. CNTF regulation of astrogliosis and the activation of microglia in the developing rat central nervous system. Brain Res. 1995, 685, 55-67. [CrossRef]

35. Cen, L.P.; Luo, J.M.; Zhang, C.W.; Fan, Y.M.; Song, Y.; So, K.F.; van Rooijen, N.; Pang, C.P.; Lam, D.S.; Cui, Q. Chemotactic effect of ciliary neurotrophic factor on macrophages in retinal ganglion cell survival and axonal regeneration. Investig. Ophthalmol. Vis. Sci. 2007, 48, 4257-4266. [CrossRef] [PubMed]

36. Lee, T.I.; Yang, C.S.; Fang, K.M.; Tzeng, S.F. Role of ciliary neurotrophic factor in microglial phagocytosis. Neurochem. Res. 2009, 34, 109-117. [CrossRef] [PubMed]

37. Kang, S.S.; Keasey, M.P.; Cai, J.; Hagg, T. Loss of neuron-astroglial interaction rapidly induces protective CNTF expression after stroke in mice. J. Neurosci. 2012, 32, 9277-9287. [CrossRef] [PubMed]

38. Chung, Y.-C.; Ko, H.-W.; Bok, E.-G.; Park, E.-S.; Huh, S.-H.; Nam, J.-H.; Jin, B.-K. The role of neuroinflammation on the pathogenesis of Parkinsons disease. BMB Rep. 2010, 43, 225-232. [CrossRef] [PubMed] 
39. Peterson, L.J.; Flood, P.M. Oxidative stress and microglial cells in Parkinson's disease. Mediat. Inflamm. 2012. [CrossRef] [PubMed]

40. Berndt, C.; Lillig, C.H. Glutathione, Glutaredoxins, and Iron. Antioxid. Redox Signal. 2017. [CrossRef] [PubMed]

41. Venkateshappa, C.; Harish, G.; Mythri, R.B.; Mahadevan, A.; Bharath, M.M.; Shankar, S.K. Increased oxidative damage and decreased antioxidant function in aging human substantia nigra compared to striatum: Implications for Parkinson's disease. Neurochem. Res. 2012, 37, 358-369. [CrossRef] [PubMed]

42. Mischley, L.K.; Allen, J.; Bradley, R. Coenzyme Q10 deficiency in patients with Parkinson's disease. J. Neurol. Sci. 2012, 318, 72-75. [CrossRef] [PubMed]

43. Lee, M.Y.; Kim, C.J.; Shin, S.L.; Moon, S.H.; Chun, M.H. Increased ciliary neurotrophic factor expression in reactive astrocytes following spinal cord injury in the rat. Neurosci. Lett. 1998, 255, 79-82. [CrossRef]

44. Park, C.K.; Ju, W.K.; Hofmann, H.D.; Kirsch, M.; Ki Kang, J.; Chun, M.H.; Lee, M.Y. Differential regulation of ciliary neurotrophic factor and its receptor in the rat hippocampus following transient global ischemia. Brain Res. 2000, 861, 345-353. [CrossRef]

45. Kong, W.L.; Peng, Y.Y.; Peng, B.W. Modulation of neuroinflammation: Role and therapeutic potential of TRPV1 in the neuro-immune axis. Brain Behav. Immun. 2017, 64, 354-366. [CrossRef] [PubMed]

46. Paxinos, G.; Watson, C. The Rat Brain in Stereotaxic Coordinates, 6th ed.; Academic Press/Elsevier: Amsterdam, The Netherlands; Boston, MA, USA, 2007.

47. Choi, S.H.; Joe, E.H.; Kim, S.U.; Jin, B.K. Thrombin-induced microglial activation produces degeneration of nigral dopaminergic neurons in vivo. J. Neurosci. 2003, 23, 5877-5886. [CrossRef] [PubMed]

48. Veldhuis, W.B.; van der Stelt, M.; Wadman, M.W.; van Zadelhoff, G.; Maccarrone, M.; Fezza, F.; Veldink, G.A.; Vliegenthart, J.F.; Bar, P.R.; Nicolay, K.; et al. Neuroprotection by the endogenous cannabinoid anandamide and arvanil against in vivo excitotoxicity in the rat: Role of vanilloid receptors and lipoxygenases. J. Neurosci. 2003, 23, 4127-4133. [CrossRef] [PubMed]

49. Christoph, T.; Bahrenberg, G.; De Vry, J.; Englberger, W.; Erdmann, V.A.; Frech, M.; Kogel, B.; Rohl, T.; Schiene, K.; Schroder, W.; et al. Investigation of TRPV1 loss-of-function phenotypes in transgenic shRNA expressing and knockout mice. Mol. Cell. Neurosci. 2008, 37, 579-589. [CrossRef] [PubMed] 